\title{
Evaluation of red blood cell distribution width in patients with cardiac syndrome $\mathrm{X}$
}

\author{
Ping Qing ${ }^{\mathrm{a}, 1}$, Song-Hui Luo ${ }^{\mathrm{a}, \mathrm{b}, 1}$, Yuan-Lin Guo ${ }^{\mathrm{a}}$, Jun Liu ${ }^{\mathrm{a}}$, Rui-Xia Xua ${ }^{\mathrm{a}}$, Cheng-Gang Zhu ${ }^{\mathrm{a}}$, \\ Yan-Jun Jia ${ }^{\mathrm{a}}$, Feng-Lian $\mathrm{Ma}^{\mathrm{a}}$, Na-Qiong $\mathrm{Wu}^{\mathrm{a}}$, Li-Xin Jiang ${ }^{\mathrm{a}}$ and Jian-Jun $\mathrm{Li}^{\mathrm{a}, *}$ \\ ${ }^{a}$ Division of Dyslipidemia, State Key Laboratory of Cardiovascular Disease, Fu Wai Hospital, National Center for \\ Cardiovascular Disease, Chinese Academy of Medical Sciences and Peking Union Medical College, Beijing, China \\ ${ }^{\mathrm{b}}$ Department of Cardiology, Fifth Hospital of Wuhan City, Wuhan, Hubei, China
}

\begin{abstract}
.
BACKGROUND: Cardiac syndrome $\mathrm{X}$ (CSX) is a condition characterized by chest pain with normal coronary arteries. However, its pathogenesis has not fully been understood yet. Red blood cell distribution width (RDW) has recently been suggested as a marker of acute and chronic cardiovascular diseases, while no data is available in patients with CSX.

METHODS: One hundred and twenty consecutive patients with CSX and 102 normal controls were prospectively enrolled in this study. Blood samples were drawn from all individuals for measuring RDW and high-sensitivity C-reactive protein (CRP). The baseline data were compared between patients with CSX and normal controls.

RESULTS: The RDW levels were significantly higher in patients with CSX than that in those with normal controls (13.1 \pm 2.1 versus $12.3 \pm 1.8, p=0.011)$. Moreover, the data showed that the levels of plasma CRP were marked higher in patients with CSX than those that were observed in normal controls (CRP: $2.8 \pm 2.2 \mathrm{mg} / \mathrm{L}$ versus $2.0 \pm 1.7 \mathrm{mg} / \mathrm{dl}, p=0.014$ ). In addition, the multivariate analysis indicated that peripheral monocyte cell, CRP and RDW were the independent variables most strongly associated with CSX. In a receiver operating characteristic (ROC) curve analysis, we found that an RDW value of $12.8 \%$ was used as an effective cut-point in the segregation of the presence or absence of cardiac syndrome X, a sensitivity of $52.0 \%$ and a specificity of $65.4 \%$ were obtained. Finally, correlation analysis suggested that there was positive correlation between plasma levels of CRP and RDW levels $(n=120, \gamma=0.381, P=0.013)$.

CONCLUSIONS: The present study, for the first time, demonstrated that elevated RDW and CRP levels were independently associated with the presence of CSX.
\end{abstract}

Keywords: Cardiac syndrome X, Red cell distribution width, C-reactive protein, complete blood count

\section{Introduction}

Cardiac Syndrome $\mathrm{X}$ is a clinical entity characterized by angina-like chest discomfort, positive treadmill exercise test, negative intravenous ergonovine test and angiographically normal $[1,2]$. During past several

\footnotetext{
${ }^{1}$ These authors contributed equally.

${ }^{*}$ Corresponding author: Jian-Jun Li, Division of Dyslipidemia, State Key Laboratory of Cardiovascular Disease, Fu Wai Hospital, National Center for Cardiovascular Disease, Chinese Academy of Medical Sciences and Peking Union Medical College, Beijing 100037, China. Tel.: +86 10 88396077; Fax: +86 10 68331730; E-mail: lijnjn@yahoo.com.cn.
}

decades of years the underlying pathogenesis of this syndrome has been poorly understood in spite of the extensive studies.

Red blood cell distribution width (RDW) is a measure of the variability in the size of circulating erythrocytes, and it has commonly been utilized in the differential diagnosis of anemia [3,4]. More recently, RDW has been shown to be a marker and independent predictor in a variety of cardiovascular diseases including acute coronary syndromes [5], stable angina [6], heart failure [7], peripheral vascular disease [8], stroke [9], old age [10], coronary artery ectasia [11], postinterventional thrombosis, poor myocardial perfusion following percutaneous coronary intervention after acute 
myocardial infarction $[12,13]$ and also general population, even after adjustment for hematocrit [14]. However, the investigation of RWD in cardiac syndrome X, a condition associated with endothelial activation and coronary microvascular dysfunction, has not been performed up to date. Moreover, emerging data suggested that inflammation might play a role in microvascular dysfunction in patients with cardiac syndrome $\mathrm{X}$, and $\mathrm{C}$-reactive protein (CRP) might a promising marker for this disorder [15-17].

Given that elevated RDW is widely recognized in several cardiovascular diseases, and the mechanism of increased RDW in patients with cardiovascular diseases is possibly associated with inflammation [4-14]. The aim of the present study was to investigate whether increased RDW is a marker for predicting the presence of cardiac syndrome $\mathrm{X}$. The relationship between RDW and CRP levels in patients with cardiac syndrome $\mathrm{X}$ was also examined in this study.

\section{Methods}

\subsection{Study population}

This was an observational study derived from a cohort of patients prospectively entered into a database for the purpose of assessing the prognostic significance of various plasma biomarkers in patients with known or suspected coronary artery disease in our division of the Fu Wai Hospital. The study was approved by the local ethics committee, and complied with the Declaration of Helsinki. The population was prospectively selected from consecutive patients (a total of 4287 patients) who underwent coronary angiography between December 2009 and March 2012 due to the presence of angina-like chest pain and/or positive treadmill exercise test. Finally, 120 patients with cardiac syndrome $\mathrm{X}$ were enrolled into the study. Entry criteria of cardiac syndrome $\mathrm{X}$ were typical angina-like chest pain, normal 12-lead electrocardiogram at rest, a positive exercise test response $(>0.1 \mathrm{mV}$ ST-segment depression at $80 \mathrm{~ms}$ after the $\mathrm{J}$ point in two or more contiguous leads) and a complete normal coronary angiogram. The normal controls were defined as (1) the presence of anginal chest pain, (2) a normal coronary angiography, and (3) no ischemia on myocardial perfusion scintigraphy or during the treadmill exercise test. Normal control consisted of 102 individuals who presented with (1) anginal chest pain; (2) no ischemia on myocardial perfusion scintigraphy or during the treadmill exercise test; (3) a normal coronary angiography.
All individuals with cardiac syndrome $\mathrm{X}$ or normal controls enrolled in this study had normal hepatic and renal function. Patients with evidence of myocardial infarction, valvular heart disease, left ventricular dysfunction, congestive heart failure, a history of dysphagia, swallowing as well as intestinal motility disorders, untreated thyroid disease, sinus node dysfunction or conduction disturbance, estrogen replacement therapy, autoimmune disease, and recent infection (within 3 months) were excluded from the study. In addition, subjects were also excluded from this study if they have had previous history of anemia, have received previous red blood cell transfusion or were on treatment for anemia, such as supplemental iron, folate or an erythropoiesis-stimulating agent. Patients with known hematological disease such as hemolytic anemia, neoplastic metastases to the bone marrow, iron replacement therapy that could increase plasma RDW levels were not included in the present study.

Baseline characteristics of all subjects were recorded including age, sex, body mass index, diabetes mellitus, hypertension, dyslipidemia, smoking, family history of coronary artery disease, left ventricular ejection fraction, creatinine, and medications were recorded.

\subsection{Angiographic examination}

The selective coronary angiography for all enrolled individuals including patients with cardiac syndrome $\mathrm{X}$ and normal control was performed using the standard Judkin's techniques, and the results were analyzed by at least two interventional physicians according to our previous study [18]. Only angiograms with visually smooth contours with no wall irregularities were considered as normal. To exclude the possibility of coronary spasm, all patients underwent hyperventilation tests during coronary angiography, which was performed by asking the patients to breathe quickly and deeply for at least 5 minutes.

\section{3. $C R P$ and RDW measurement}

EDTA-anticoagulated peripheral blood sample were taken after 12-hour overnight fast at baseline. The plasma was obtained after a centrifugation of 3000 rpm at $4{ }^{\circ} \mathrm{C}$ for 15 minutes. The levels of highsensitivity CRP were determined using immunoturbidometry (Beckmann Assay 360) as our previously reported [18]. The median normal value for CRP is $0.08 \mathrm{mg} / \mathrm{dl}$, with $90 \%$ of normal values $<0.03 \mathrm{mg} / \mathrm{dl}$, with a lower detection limit of $0.02 \mathrm{mg} / \mathrm{dl}$. The inter- 
Table 1

Baseline clinical characteristics (mean $\pm \mathrm{SD})$

\begin{tabular}{|c|c|c|c|}
\hline Variables & $\begin{array}{c}\text { Cardiac syndrome } \mathrm{X} \\
\quad(n=120)\end{array}$ & $\begin{array}{l}\text { Normal control } \\
\quad(n=102)\end{array}$ & $\mathrm{p}$ value \\
\hline Age (years) & $48 \pm 8$ & $49 \pm 8$ & 0.620 \\
\hline $\operatorname{Sex}(F / M)$ & $97 / 23$ & $88 / 14$ & 0.472 \\
\hline Body mass index $\left(\mathrm{kg} / \mathrm{m}^{2}\right)$ & $22 \pm 4$ & $22 \pm 3$ & 0.875 \\
\hline Family history of CAD, n (\%) & $11(9)$ & $7(7)$ & 0.373 \\
\hline Current smoker, n (\%) & $14(12)$ & $9(9)$ & 0.524 \\
\hline Hypertension, n (\%) & $56(47)$ & $31(30)$ & 0.045 \\
\hline Hperlipidemia, n (\%) & $43(36)$ & $41(40)$ & 0.183 \\
\hline Menopausal, n (\%) & $79(66)$ & $40(39)$ & 0.039 \\
\hline Diabetes, n (\%) & $14(12)$ & $10(10)$ & 0.829 \\
\hline $\operatorname{LVEF}(\%)$ & $62 \pm 7$ & $63 \pm 8$ & 0.417 \\
\hline \multicolumn{4}{|l|}{ Medications } \\
\hline Aspirin, n (\%) & $102(85)$ & $84(82)$ & 0.492 \\
\hline$\beta$-blocke, n (\%) & $30(25)$ & $14(14)$ & 0.042 \\
\hline ACEI, n $(\%)$ & $34(28)$ & $25(24)$ & 0.351 \\
\hline Statin, n (\%) & $36(30)$ & $27(26)$ & 0.080 \\
\hline $\mathrm{CCB}, \mathrm{n}(\%)$ & $17(14)$ & $17(17)$ & 0.733 \\
\hline
\end{tabular}

$\overline{\mathrm{CAD}}=$ coronary artery disease; $\mathrm{LVEF}=$ left ventricular ejection fraction; $\mathrm{LVEF}=$ left ventricular ejection fraction; $\mathrm{ACEI}=$ angiotensinconverting enzyme inhibitor; $\mathrm{CCB}=$ calcium channel blocker.

assay and intra-assay coefficients of variation were from 4.5 and $5.1 \%$, respectively.

Hemoglobin, RDW, and white blood cell (WBC) count were also determined after admission by the automated hematology analyzer XE-1200 (Sysmex, Kobe, Japan). The normal range of RDW (\%) in our hospital laboratory was $10-16 \%$. The other biochemical measurements were performed using a molecular analyzer (Roche Diagnostics, Manheim, Germany).

\subsection{Statistical analysis}

Statistical analyses were carried out using SPSS 15.0 (SPSS Inc., Chicago, Illinois, USA) software. Continuous variables are expressed as mean $\pm \mathrm{SD}$, and categorical variables were expressed as percentage. Comparison of continuous variables between the two groups was performed using Student $t$ test and/or Mann-Whitney $U$ test. The chi-square test, or the Fisher exact test was used to compare the categorical variables between the two groups. Because the distribution of CRP is skewed rightward, log transformation was made at baseline, and the significance of any difference in distributions was assessed by the Wilcoxon rank-sum test as our previously reported [18]. The univariate and multivariate analysis was used for baseline clinical characteristics, inflammatory biomarkers, and RDW. Association between RDW and CRP was test using Spearman correlation coefficient. Receiver operating characteristic (ROC) curve analysis was performed to define the optimal CAD-specific cut-off points. A $\mathrm{p}$ value $<0.05$ was considered statistically significant.

\section{Results}

\subsection{Baseline clinical characteristics}

Baseline clinical characteristics of the study population are given in Table 1. There were no significant differences between the two groups with respect to age, body mass index, blood pressure, smoking consumption, lipid profile, diabetes, function of left ventricle. However, the percentage of Hypertension, menopausal, and $\beta$-blocker treatment was significantly higher in patients with cardiac syndrome $\mathrm{X}$ group compared with control group.

\subsection{Laboratory findings}

Laboratory findings from individuals with cardiac syndrome and those with normal controls are summarized in Table 2. As showed in Table 2, the RDW levels in patients with cardiac syndrome $X$ were significantly higher compared with normal controls $(13.1 \pm 2.1$ versus $12.3 \pm 1.8, p=0.011)$. And also, plasma CRP levels in patients with cardiac syndrome $\mathrm{X}$ were much higher than that in those with normal controls, which was 1.33 -fold higher in patients with cardiac syndrome $\mathrm{X}$ compared with normal controls $(2.8 \pm 2.2 \mathrm{mg} / \mathrm{dl}$ versus $2.0 \pm 1.7 \mathrm{mg} / \mathrm{dl}, p=0.014)$. Moreover, The data also showed an increased numbers of white blood cells in patients with cardiac syndrome X compared with normal controls $\left(6834 \pm 1072 / \mathrm{mm}^{3}\right.$ vs $6015 \pm$ $\left.1153 / \mathrm{mm}^{3}, p=0.047\right)$. Similarly, the peripheral circulating monocyte cells were significantly higher in pa- 
Table 2

Laboratory findings (mean $\pm \mathrm{SD})$

\begin{tabular}{|c|c|c|c|}
\hline Variables & $\begin{array}{c}\text { Cardiac syndrome } \mathrm{X} \\
(n=120)\end{array}$ & $\begin{array}{l}\text { Normal control } \\
\quad(n=102)\end{array}$ & $\bar{p}$ value \\
\hline Creatinine, $(\mathrm{mg} / \mathrm{dl})$ & $0.86 \pm 0.54$ & $0.89 \pm 0.58$ & 0.484 \\
\hline White blood cell $\left(/ \mathrm{mm}^{3}\right)$ & $6834 \pm 1072$ & $6015 \pm 1153$ & 0.047 \\
\hline Monocyte count $\left(/ \mathrm{mm}^{3}\right)$ & $608 \pm 170$ & $521 \pm 175$ & 0.025 \\
\hline Erythrocyte count $\left(10^{12} / \mathrm{L}\right)$ & $4.3 \pm 0.5$ & $4.3 \pm 0.4$ & 0.427 \\
\hline Hemoglobin, $(\mathrm{g} / \mathrm{dl})$ & $13.1 \pm 1.3$ & $12.8 \pm 1.2$ & 0.651 \\
\hline Mean corpuscular volume (fL) & $85 \pm 4.7$ & $86 \pm 4.3$ & 0.377 \\
\hline hs-CRP (mg/dl) & $2.8 \pm 2.2$ & $2.0 \pm 1.7$ & 0.014 \\
\hline RDW $(\%)$ & $13.1 \pm 2.1$ & $12.3 \pm 1.8$ & 0.011 \\
\hline
\end{tabular}

$\mathrm{Hs}-\mathrm{CRP}=$ high-sensitivity $\mathrm{C}$-reactive protein; RDW=red blood cell distribution width.

Table 3

Predictors of cardiac syndrome $\mathrm{X}$ in univariate and multivariate logistic regression analysis

\begin{tabular}{|c|c|c|c|c|c|c|}
\hline \multirow[t]{2}{*}{ Variables } & \multicolumn{2}{|c|}{ Univariate } & \multirow[t]{2}{*}{ P-values } & \multicolumn{2}{|c|}{ Multivariate } & \multirow[t]{2}{*}{ P-values } \\
\hline & OR & $95 \% \mathrm{CI}$ & & OR & $95 \% \mathrm{CI}$ & \\
\hline Hypertension, n (\%) & 1.207 & $1.034-1.779$ & 0.050 & 0.972 & $0.991-1.676$ & 0.070 \\
\hline Menopausal, n (\%) & 1.275 & $1.162-1.812$ & 0.047 & 0.891 & $0.974-1.648$ & 0.192 \\
\hline $\mathrm{WBC},\left(/ \mathrm{mm}^{3}\right)$ & 1.291 & $1.072-1.843$ & 0.054 & 0.977 & $0.935-1.749$ & 0.131 \\
\hline $\mathrm{PMC},\left(/ \mathrm{mm}^{3}\right)$ & 1.344 & $1.167-1.902$ & 0.043 & 1.250 & $1.103-1.842$ & 0.004 \\
\hline Hs-CRP, (mg/dl) & 2.052 & $1.380-3.642$ & 0.011 & 1.173 & $1.152-2.905$ & 0.001 \\
\hline RDW, $\%$ & 1.926 & $1.319-2.581$ & 0.013 & 1.405 & $1.291-2.956$ & 0.000 \\
\hline
\end{tabular}

$\overline{\mathrm{WBC}}=$ white blood count; PMC $=$ peripheral monocyte count; Hs-CRP $=$ high-sensitivity C-reactive protein; RDW $=$ red cell distribution width.

tients with cardiac syndrome $\mathrm{X}$ compared with normal controls $\left(608 \pm 170 / \mathrm{mm}^{3}\right.$ vs $521 \pm 175 / \mathrm{mm}^{3}, p=$ $0.025)$. However, there was no significant difference in hemoglobin levels between the two groups $(13.1 \pm 1.3$ $\mathrm{g} / \mathrm{dl}$ vs $12.8 \pm 1.2 \mathrm{~g} / \mathrm{dl}, p=0.651)$.

\subsection{Univariate and multivariate analysis}

All 6 variables associated with cardiac syndrome $\mathrm{X}$ including hypertension, menopausal, peripheral circulating white blood cell, monocyte cell, CRP and RDW with $p<0.05$ in univariate analysis are presented in Table 3, (hypertension: odds ratio 1.207 , 95\% confidence interval 1.034 to $1.779, p=0.050$; Menopausal: odds ratio $1.275,95 \%$ confidence interval 1.162 to $1.812, p=0.047$; White blood cell: odds ratio 1.291. $95 \%$ confidence interval 1.072 to $1.843, p=0.054$; monocyte cell: odds ratio $1.344 .95 \%$ confidence interval 1.167 to $1.902, p=0.043$; CRP: odds ratio 2.052. $95 \%$ confidence interval 1.380 to $3.642, p=$ 0.011 ; RDW: odds ratio $1.926 .95 \%$ confidence interval 1.319 to $2.581, p=0.013$ ). And then, we put those 6 variables into the multivariate analysis. Interestingly, we found that peripheral monocyte cell, hs-CRP and RDW were the independent variables most strongly associated with cardiac syndrome $\mathrm{X}$ (peripheral moncyte cell: odds ratio $1.250,95 \%$ confidence interval 1.103 to $1.842, p=0.004$; hs-CRP: odds ratio $1.173,95 \%$ con- fidence interval 1.152 to $2.905, p=0.001$; RDW: odds ratio $1.405,95 \%$ confidence interval 1.291 to 2.956 , $p=0.000$; Table 3).

\subsection{ROC curve and correlation analysis}

In a ROC curve analysis with area under curve $($ AUC $)=0.61,95 \% \mathrm{CI}: 0.56-0.66$, we found that an RDW value of $12.8 \%$ was used as an effective cutpoint in the segregation of the presence or absence of cardiac syndrome $\mathrm{X}$, a sensitivity of $52.0 \%$ and a specificity of $65.4 \%$ were obtained (Fig. 1).

We also examined the correlation of RDW with CRP levels in patients with cardiac syndrome X. As shown in Fig. 2, there was a positive correlation between RDW and plasma levels of CRP in patients with cardiac syndrome $\mathrm{X}(n=120, \gamma=0.381, P=0.013)$.

\section{Discussion}

The main findings of the present study are that (1) RDW level was significantly higher in patients with cardiac syndrome X compared with normal control; (2) the baseline RDW levels were independent predictor for this disease condition; (3) a positive correlation between RDW level and plasma concentration of CRP in patients with cardiac syndrome $\mathrm{X}$. 


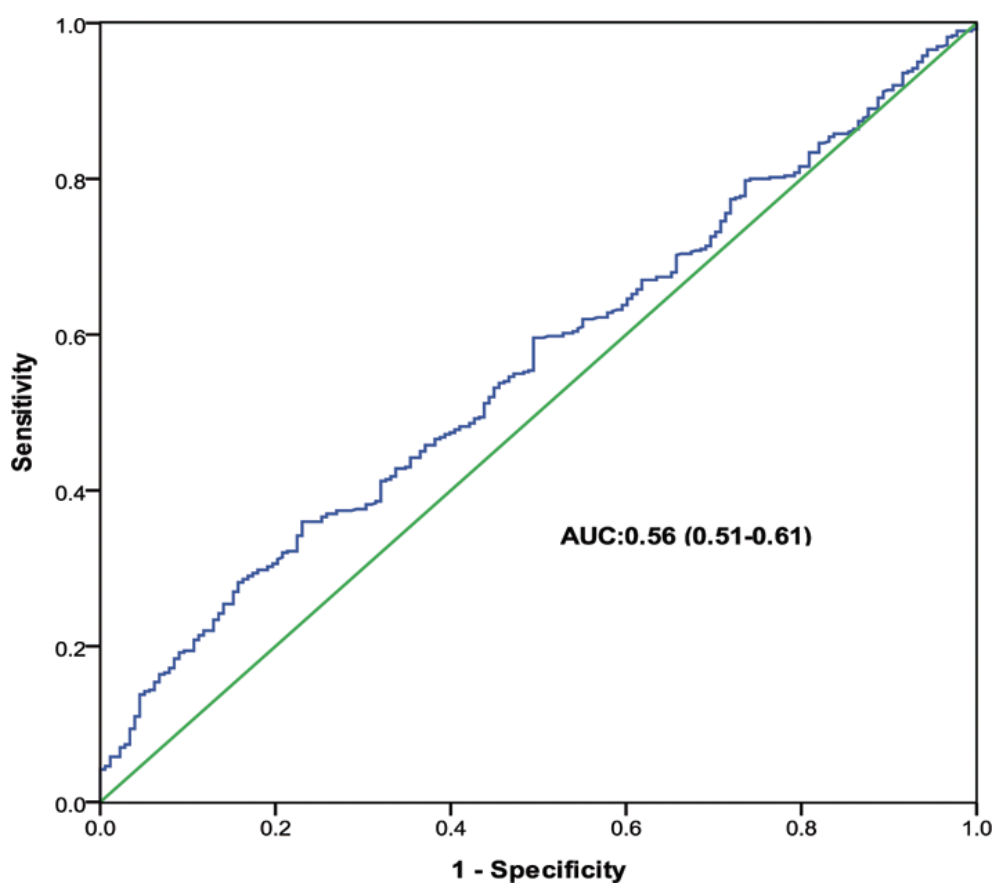

Fig. 1. The results of Receiver operating characteristic curve (ROC) analysis. Identification of a cut off value for red cell distribution width (RDW) in patients with cardiac syndrome $\mathrm{X}$ by a ROC analysis. AUC $=$ area under the curve. (Colours are visible in the online version of the article; http://dx.doi.org/10.3233/DMA-130977)

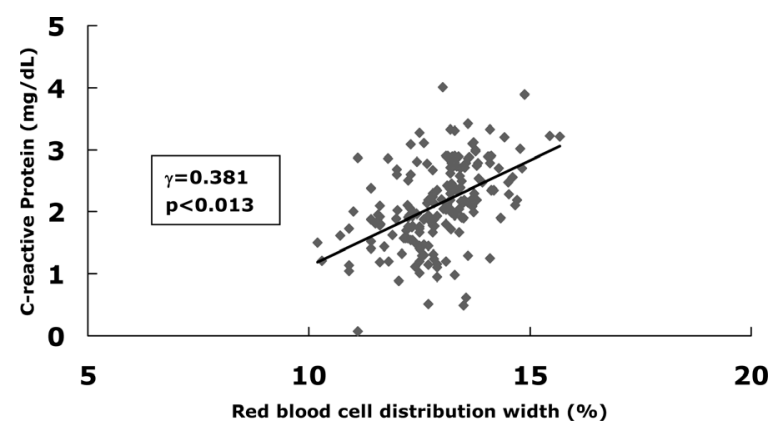

Fig. 2. Correlation analysis of plasma CRP levels and RDW in patients with cardiac syndrome $\mathrm{X}$. There were marked positive correlation between the plasma levels of CRP and RDW $(\gamma=0.381, p=$ $0.013)$.

It has been well recognized that chest pain with normal coronary arteries are termed as cardiac syndrome $\mathrm{X}$. The patients with this syndrome often complain of debilitating and excruciating chest pain despite the presence of normal coronary arteries on angiography [15]. Although cardiac syndrome $X$ is not associated with an increased risk of death, it often severely impairs quality of life and represents a substantial cost burden to the health care system [16]. Although the exact mechanism by which cardiac syndrome $\mathrm{X}$ developed, remains unknown, coronary microvascular dys- function and earlier, silent atherosclerosis has been suggested as two major contributors [19].

Generally, elevated RDW results from heterogeneity and erythrocyte size and erythrocyte fragmentation in the circulation. RDW is commonly used, in combination with mean corpuscle volume, as an indicator of differential diagnosis of anemia [3,4]. Factors that contribute to increased erythrocyte size heterogeneity include iron or vitamin B12/folate deficiency, decreased erythrocyte life-span, impaired erythropoiesis and factors that contribute to erythrocyte fragmentation including increased fragility and destruction of red cell [20,21]. However, increased RDW has recently been found to be a strong and independent predictor of increased risk of mortality and adverse cardiovascular outcomes in patients with acute and chronic cardiovascular diseases [5-13]. There is no data available in the current literatures regarding the relationship between RWD and cardiac syndrome X despite the evidence of the role of RDW in a variety of cardiovascular diseases. In the present study we extended previous studies and for the first time found that RDW was significantly higher in patients with cardiac syndrome $\mathrm{X}$ compared with normal controls $(13.1 \pm 2.1$ versus $12.3 \pm 1.8, p=0.011)$.

The exact illustration of correlation between higher levels of RDW and the presence of cardiac syndrome X 
is unclear. One of the most possible mechanisms may be related to inflammation. In fact, emerging findings have suggested a role of inflammation in coronary endothelial dysfunction in cardiac syndrome X [19,2227]. Tousoulis et al., found that serum levels of vascular cell adhesion molecule-1 (VCAM-1) and intercellular adhesion molecule-1 (ICAM-1) were significantly higher in patients with cardiac syndrome X. Pathophysiologically, those adhesion molecules are usually synthesized by activated endothelial cells in response to inflammatory stimuli [22]. In accordance with those findings, data from Lanza GA, et al. also demonstrated an increased level of interleukin-1 (IL-1) receptor antagonist in patients with cardiac syndrome $\mathrm{X}$, unrelated with infectious burden [23]. More recent data showed that soluble CD40 ligand (sCD40L) was associated with ischemic burden in patients with cardiac syndrome $\mathrm{X}$, suggesting the potential role of this inflammatory molecule in the pathogenesis of cardiac syndrome X deserves further investigation [24].

CRP, a marker of chronic inflammation and a predictor of vascular events, has been associated with impaired endothelial function in patients with either coronary artery disease or cardiac syndrome X. Elevated CRP has also been demonstrated to be correlated with the activity of the disease in patients with cardiac syndrome X [23]. Cosin-Sales et al. indicated that CRP levels were associated with electrocardiogram markers of myocardial ischemia and disease activity [25]. As similarly observed in patients with coronary artery disease, elevated CRP levels in patients with cardiac syndrome $\mathrm{X}$ have been showed to be independent of age, sex, obesity, and cholesterol levels, which suggested that inflammation might enhance the effects of certain conventional risk factors on promoting endothelial dysfunction and atherosclerosis [26,27].

In fact, RWD levels have been demonstrated to be associated with inflammatory markers such as soluble tumor necrosis factor receptor and CRP in the setting of atherosclerosis and other diseases [28]. Importantly, proinflammatory cytokines have been found to inhibit erythropoietin-induced erythrocyte maturation, which is reflected in part by an increase in RDW [6,29]. Accordingly, we hypothesized that higher values of RDW may be presented as a potential underlying inflammatory state in patients with cardiac syndrome $X$. In this small-sample size, consecutive, sex-matched study, our data showed that peripheral circulating white blood cells and monocyte cells were significantly higher in patients with cardiac syndrome X compared with normal controls. The fact that a positive correlation be- tween RDW level and plasma concentration of CRP in patients with cardiac syndrome $\mathrm{X}$ in the present study, may also support the concept that low-grade, chronic inflammation might be involved in the pathogenesis of cardiac syndrome $\mathrm{X}$.

In conclusion, our data for the first time showed that elevated RDW existed in patients with cardiac syndrome X, which was independently associated with the presence of cardiac syndrome $X$. The data also demonstrated a positive correlation between RDW and CRP levels. The results may indicate that the role of RDW in predicting the prognosis of cardiac syndrome $\mathrm{X}$ and its relation to inflammation deserves further investigation.

\section{Limitations}

Firstly, the cardiovascular events were not analyzed in the present study. Secondly, the study needs replication in other population due to the observational nature of the study. Moreover, a single center study may be also a limitations. The possibility of underlying coronary artery spasm was ruled out by hyperventilation test rather than ergonovine injection. As the specificity and the sensitivity of the hyperventilation test compared to ergonovine injection is lower, the use of hyperventilation may be a limitation of this study. However, we preferred hyperventilation test in our patients because of the possibility of persistent, and severe, painful spasm with ergonovine. Furthermore, smallsample size may also be a limitation. Finally, the other factors including iron, vitamin B12, and folate did not measured in this study.

\section{Acknowledgements}

This article is partly supported by National Natural Scientific Foundation (81070171, 81241121), Specialized Research Fund for the Doctoral Program of Higher Education of China (20111106110013), Fund of Capital Special Foundation of Clinical Application Research (Z121107001012015) awarded by Dr. JianJun Li, MD, PhD.

\section{References}

[1] Bairey Merz CN, Pepine CJ. Syndrome X and microvascular coronary dysfunction. Circulation 2011;124:1477-1480.

[2] Pizzi C, Bugiardini R. Further insight into syndrome X. Heart 2010;96: 1865-1867. 
[3] Lippi G, Targher G, Montagnana M, Salvagno GL, Zoppini G, Guidi GC. Relation between red blood cell distribution width and inflammatory biomarkers in a large cohort of unselected outpatients. Arch Pathol Lab Med 2009;133:628-632.

[4] Allen LA, Felker GM, Mehra MR, Chiong JR, Dunlap SH, Ghali JK, et al. Validation and potential mechanisms of red cell distribution width as a prognostic marker in heart failure. J Cardial Fail 2010;16:230-238.

[5] Dabbah S, Hammerman H, Markiewicz W, Aronson D. Relation between red cell distribution width and clinical outcomes after acute myocardial infarction. Am J Cardiol 2010;105:312-317.

[6] Tonelli M, Sacks F, Arnold M, Moye L, Davis B, Pfeffer M. Cholesterol and Recurrent Events Trial Investigators. Relation between red blood cell distribution width and cardiovascular event rate in peoples with coronary disease. Circulation 2008; 117:163-168.

[7] Felker GM, Allen LA, Pocock SJ, Shaw LK, McMurray JJ, Pfeffer MA, et al. Red cell distribution width as a novel marker in heart failure: data from the CHARM program and the Duke Databank. J Am Coll Cardiol 2007;50:40-47.

[8] Ye Z, Smith C, Kullo IJ. Usefulness of red cell distribution width to predict mortality in patients with peripheral artery disease. Am J Cardiol 2011;107:1241-1245.

[9] Ani C, Ovbiagele B. Elevated red blood cell distribution width to predicts mortality in persons with known stroke. J Neurol Sci 2009;277:103-108.

[10] Patel KV, Semba RD, Ferrucci L, Newman AB, Fried LP, Wallace RB, et al. Red cell distribution width and mortality in older adults: a meta-analysis. J Gerontol A Biol Sci Med Sci 2010;65:258-265.

[11] Dogdu O, Koc F, Kalay N, Yarliglues M, Elicik D, karayakali M, Ozbek K, Kaya MG. Assessment of red cell distribution width (RDW) in patients with coronary artery ectasia Clin Appl Thromb Hemost 2012;18:211-214.

[12] Karabulut A, Uyarel H, Uzunlar B, Cakmak M. Elevated red cell distribution level predicts worse postinterventional thrombosis in myocardial infarction flow reflecting abnormal reperfusion in acute myocardial infarction treated with a primary coronary intervention. Coron Artery Dis 2012;23:68-72.

[13] Lsik T, Kurt M, Ayhan E, Tanboga IH, Ergelen M, Uyarel H. The impact of admission red cell distribution width on the development of poor myocardial perfusion after primary percutaneous intervention. Atherosclerosis 2012;224:143-149.

[14] Peristein TS, Weuve J, Pfeffer MA, Beckman JA. Red blood cell distribution width and mortality risk in a communitybased prospective cohort. Arch Intern Med 2009;168:588594.

[15] Asbury EA, Collins P. Cardiac syndrome X. Int J Clin Pract 2005;59: 1063-1069.

[16] Kaski JC, Rosano GM, Collins P, Nihoyannopoulos P, Maseri
A, Poole-Wilson PA. Cardiac syndrome X: clinical characteristics and left ventricular function: long-term follow-up study. J Am Coll Cardiol 1995;25:807-814.

[17] Crea F, Lanza GA. Angina pectoris and normal coronary arteries: cardiac syndrome X. Heart 2004;90:457-463.

[18] Li J-J, Nie S-P, Qian X-W, Zeng H-S, Zgang C-Y. Chronic inflammatory status in patients with coronary artery ectasia. Cytokine 2009;46:61-64.

[19] Li J-J, Li Y-S, Zhang Y, Gao Z, Li Z, Qian H-Y. Inflammation: a possible pathogenic link to cardiac syndrome $X$. Med Hypotheses 2006;66:527-530.

[20] Nagajothi N, Braverman A. Elevated red cell distribution width in the diagnosis of thrombotic thrombocytopenic purpura in patients with presenting with anemia and thrombocytopenia. South Med J 2007;100:257-259

[21] Saigo K, Jiang M, Tanaka C, Fujimoto K, Kobayashi A, Nozu $\mathrm{K}$, et al. Usefulness of automatic detection of fragmental red cells using a hematology analyzer for diagnosis of thrombotic microangiopathy. Clin Lab Haematol 2002;24:347-351.

[22] Tousoulis D, Davies GJ, Asimakopoulos G, Homaei H, Zouridakis E, Ahmed N, Kaski JC. Vascular cell adhesion molecule-1 and intercellular adhesion molecule-1 serum level in patients with chest pain and normal coronary arteries (syndrome X). Clin Cardiol 2001;24:301-304.

[23] Lanza GA, Sestito A, Cammarota G, Grillo RL, Vecile E, Cianci R, et al. Assessment of systemic inflammation and infective pathogen burden in patients with cardiac syndrome X. Am J Cardiol 2004;94:40-44.

[24] Dominguez-Rodriguez A, Abreu-Gonzalez P, Avanzas P, Gomez MA, Kaski JC. Elevated circulating soluble form of CD40 ligand in patients with cardiac syndrome X. Atheroscleorsis 2010;213:637-641.

[25] Cosin-Sales J, Pizzi C, Brown S, Kaski JC. C-reactive protein, clinical presentation, and ischemic activity in patients with chest pain and normal coronary artery. J Am Coll Cardiol 2003;41:1468-1474.

[26] Arroyo-Espliguero R, Mollichelli N, Avanzas P, Zouridakis E, Newey VR, Nassiri DK, Kaski JC. Chronic inflammation and increased arterial stiffness in patients with cardiac syndrome X. Eur Heart J 2003;24:2006-2011.

[27] Arroyo-Espliguero R, Kaski JC. Microvascular dysfunction in cardiac syndrome $\mathrm{X}$ : the role of inflammation. CMAJ 2006;174:1833-1834

[28] Lee WS, Kim TY. Relation between red cell blood distribution width and inflammatory biomarkers in rheumatoid arthritis. Arch Pathol Lab Med 2010;134:505-506.

[29] Papadaki HA, Kritikos HD, Valatas V, Boumpas DT, Eliopoulos GD. Anemia of chronic disease in rheumatoid arthritis is associated with increased apoptosis of bone marrow erythroid cells: improvement following anti-tumor nerosis factor-alpha antibody therapy. Blood 2002;100:474-482. 


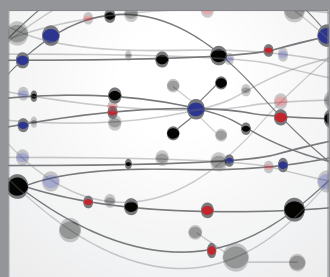

The Scientific World Journal
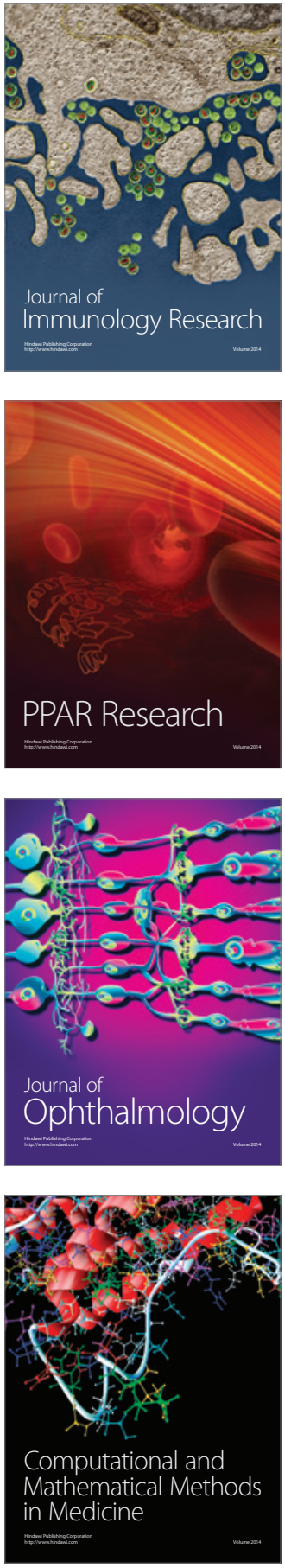

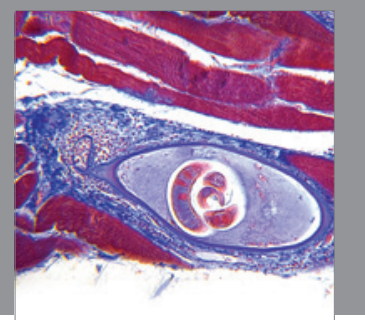

Gastroenterology

Research and Practice
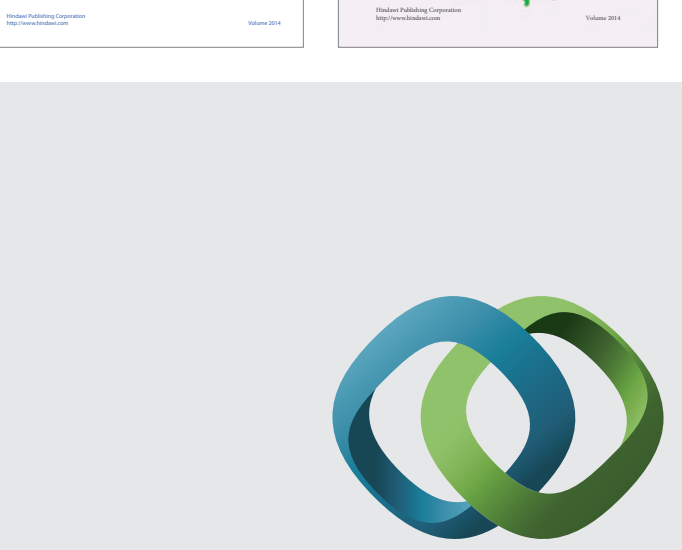

\section{Hindawi}

Submit your manuscripts at

http://www.hindawi.com
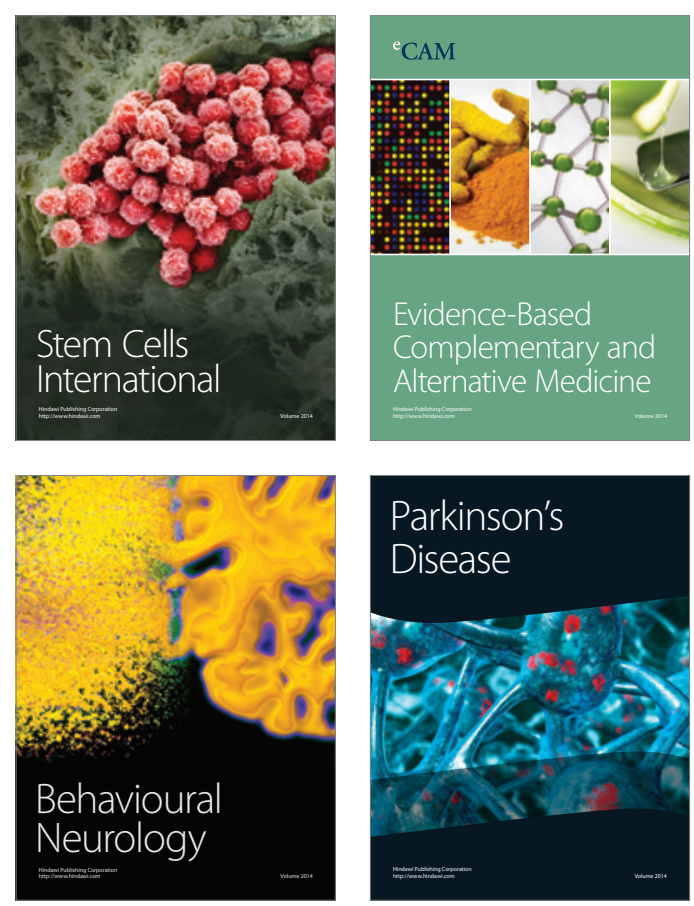

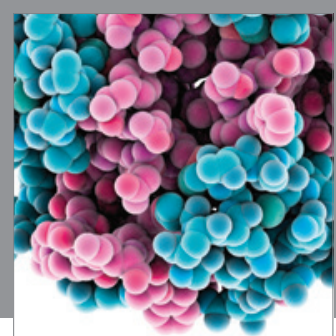

Journal of
Diabetes Research

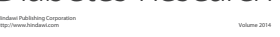

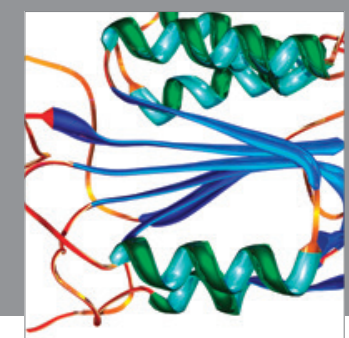

Disease Markers
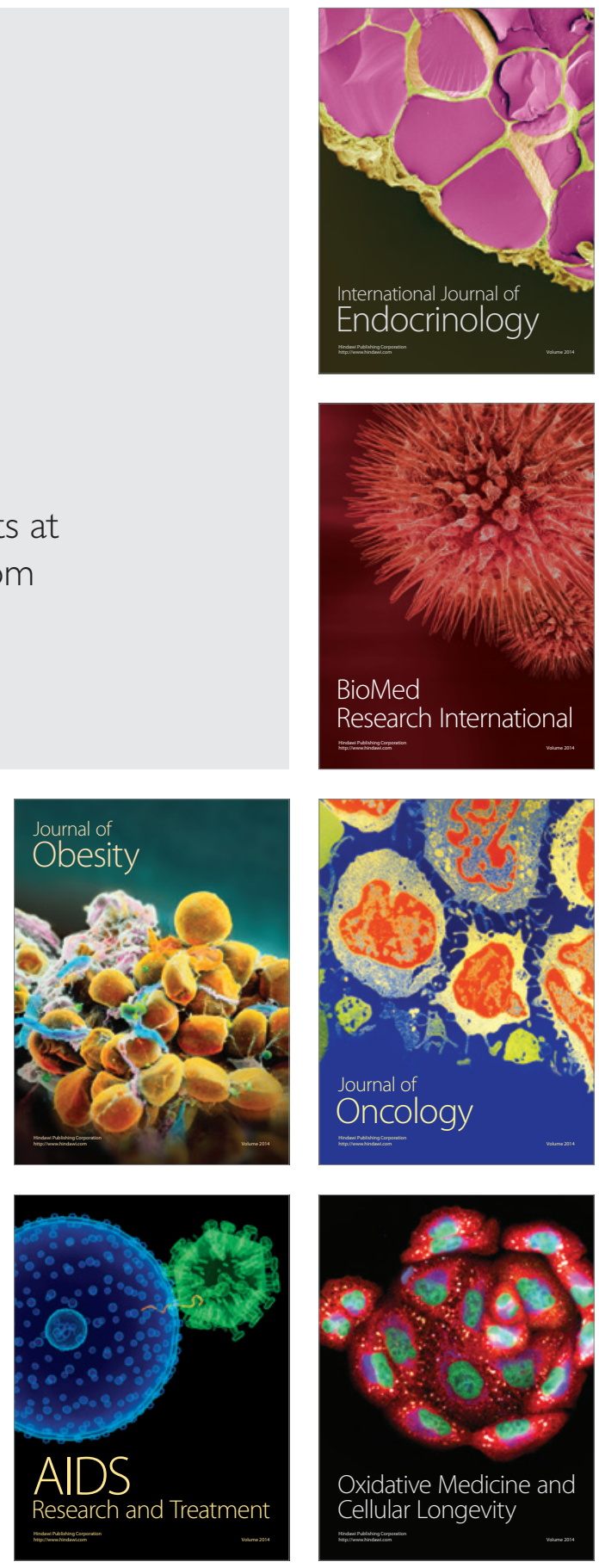